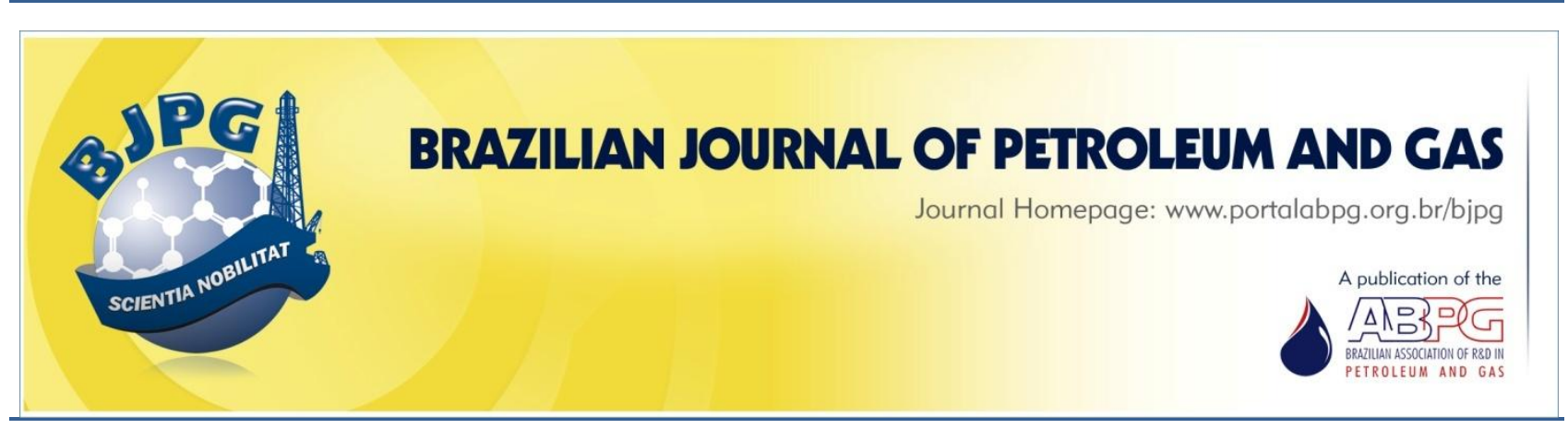

\title{
COMPARATIVE ANALYSIS OF PENETRATION RATES USING DOWNHOLE MOTOR AND ROTARY STEERABLE SYSTEM IN AN ONSHORE DIRECTIONAL HOLE
}

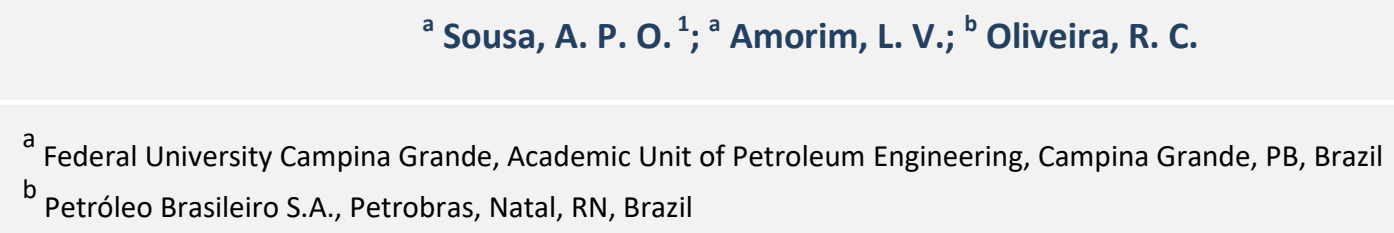

\begin{abstract}
Directional drilling is a costly method used in drilling operations, as it requires investments in special tools such as downhole motor and rotary steerable system (RSS). This paper performs a comparative study between the penetration rates achieved when using downhole motor and RSS tools. To make the study feasible, the drilling of the 8 3/4 in diameter phase of an onshore directional hole, comprised between 197 $\mathrm{m}$ and $957 \mathrm{~m}$, was analyzed using the equipment referenced. The average penetration rates and the costs generated by each one of them were calculated as a function of the total operating time. Considering these parameters, we found that the use of downhole motor was more advantageous than using the rotary steerable system because, despite its longer operating time, it presented much lower costs.
\end{abstract}

\section{KEYWORDS}

directional drilling; operation; equipment; costs; economic viability

\footnotetext{
${ }^{1}$ To whom all correspondence should be addressed. Address: Federal University of Campina Grande / Academic Unit of Petroleum Engineering, Rua Aprígio Veloso, 882, Bloco CA2, Campus Universitário, Campina Grande, PB, Brazil. Phone number: +55 (83) 99820-6290 | e-mail: anap.olvs@gmail.com doi:10.5419/bjpg2020-0005
} 


\section{INTRODUCTION}

The drilling of oil wells, since its inception, is a complex activity that involves great risks and high financial costs. Directional drilling allows maximizing the recovery of reservoirs, exploring oil fields in locations that are difficult to access while providing an increase well productivity (Almeida, 2002). In addition, this method covers one of the most expanded branches of the oil industry over the years, since the need to drill increasingly complex wells has stimulated the improvement of drilling technologies. However, according to Paes et al. (2005), directional drilling elevates the costs of drilling operations, as it requires investments in special equipment, such as downhole motor and rotary steerable system (RSS).

In directional wells, the kick-off point (KOP) is achieved by using downhole motor, in shallow depth, usually in the upper regions of the well, where the diameter is larger. However, in these regions, motors offer low rates of penetration (ROP) and can form irregular wells. In response to this problem, the KOP should remain located at shallow depths, followed by the use of an RSS. As a result, drilling engineers observed that the use of this tool reduced the drilling time by $63 \%$ compared to the use of downhole motors used in sections of nearby wells (Willson et al., 2004). Drilling costs are time-dependent (Amorim Jr, 2008). Any method that helps increase ROP and preserve the bit will lead to time reduction (Küng, 2016).

The latest versions of RSS tools are capable of producing wells with uniform diameters, which are more stable and less subject to deformation than those produced by using a downhole motor.
However, the utilization of RSS is more expensive than the use of downhole motor, because it has a more complex system, both mechanically and electronically (Chen, 2006).

Thus, complementary studies are necessary to evaluate the influence of this equipment on the penetration rate of a well, ensuring the best practices in the operation. This work performs a comparative study between penetration rates using downhole motor and rotary steerable system tools.

\section{DIRECTIONAL DRILLING}

Directional drilling is a technique used in the oil industry to reach targets located in different coordinates than those of the wellhead (Rocha, 2008). This method was developed based on the need to execute deviations in the well path, due to obstructions (Machado, 2010), as shown in Figure 1.

According to Thomas (2001), directional wells are drilled for various purposes such as:

- Drilling several wells from the same point, as in offshore productions;

- Reaching formations that are below inaccessible locations;

- Controlling a well in blowout through the drilling of relief wells;

- Deviating the trajectory of the well from geological accidents; and

- Diverting wells which have lost their final section due to operational problems.

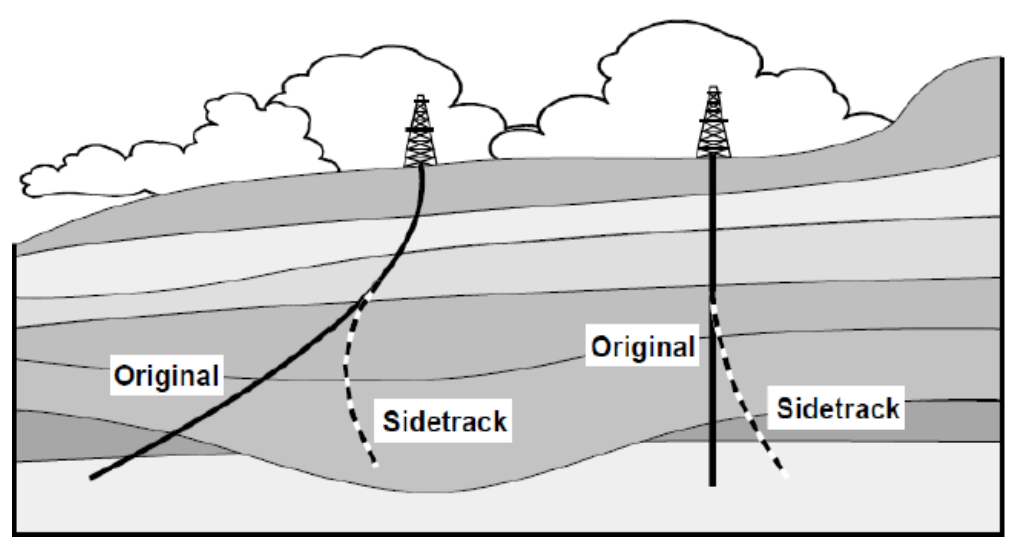

Figure 1. Wells with secondary branches (sidetrack) (Inteq / Baker Hughes, 1995). 
In this context, although the principles of this modality are basically the same nowadays, the development of equipment and control instruments led to the creation of a true science, called Directional Drilling (Machado, 2010).

\subsection{Directional path: Planning of a well}

The path run by the bit, starting from the wellhead until reaching the target, or the end of the well, is called a directional path (Lourenço Jr, 2012). To achieve a successful drilling a directional well, it is necessary to plan its path. With the advancement of technology and the consequent evolution of directional drilling, it became possible to perform increasingly complex trajectories effectively. During drilling, some adjustments may be required to maintain the planned path. Depending on the level of difficulty that may arise, a more significant modification to the plan may be necessary.

According to Mims (1999), the design of a directional well must consider that the systems that make up the drilling are interrelated in regards to good wellbore cleanup. This way, it is not possible to modify the bit, the composition of the bottom-hole assembly (BHA), the drilling fluid, or even the drilling parameters without considering the impact of these elements on the performance of each other. Therefore, the planning of directional wells should be promoted based on previous studies and detailed data, to avoid possible design flaws that may lead to economic and environmental losses.

\subsection{Rate of penetration (ROP)}

The rate of penetration (ROP) is the value that expresses the speed with which the bit penetrates the rock formation while drilling an oil well (Férnandez et al., 2009). Thus, ROP is the most important reading resulting from the application of drilling parameters that can be altered by the operation managers. It is one of the indicators that help in deciding whether or not to continue the operation (Küng, 2016).

Factors affecting the penetration rate must be understood before conducting any analysis to understand the effectiveness of drilling a well based on the use of a given bit. According to Ebrahimi and Noveiri (2010), there are several factors that influence ROP, among them are:
- Bit type;

- Formation characteristics, such as porosity and permeability;

- Drilling fluid properties, such as density and viscosity;

- Drilling parameters applied, such as rotation and weight on the bit.

In addition, parameters adopted throughout the operation that go beyond the manufacturer's recommendations, such as weight and rotation values applied, and generation of bit shock with the formation due to a high-speed trip can negatively impact the bit life, and, therefore, affect the registered ROP (Küng, 2016).

\subsection{Directional drilling equipment and tools}

Before the appearance of modern directional equipment, it was possible to drill directional wells by positioning drill collar and stabilizers in the drill string. Different string compositions allowed to gain, maintain, or lose angle. In some cases, the experience gained in a certain area allowed the natural tendency of the formations to guide the well in a certain direction. Directional drilling done this way allows for a certain control of the well's inclination but provides little or no control of its direction (Lourenço Jr, 2012). For this reason, currently, some instruments can be used to drive the bit to make the designed path (Azar \& Samuel, 2007). Thus, tools for various functions, capable of generating directional wells of different types are applied in directional drilling nowadays.

\subsubsection{Downhole motor}

According to Rocha (2008), one of the basic tools in directional drilling is the downhole motor. Its main function is to convert the pressure energy of the drilling fluid into rotation and torque, which are transmitted to the bit regardless of the drill string rotation. The main components in their typical composition are: by-pass valve, power section, transmission unit, and bearing section. This composition is presented in Figure 2.

Chen (2006) stated that a steerable system is a system in which a tool set is used. The main one is the downhole motor equipped with bent sub or 


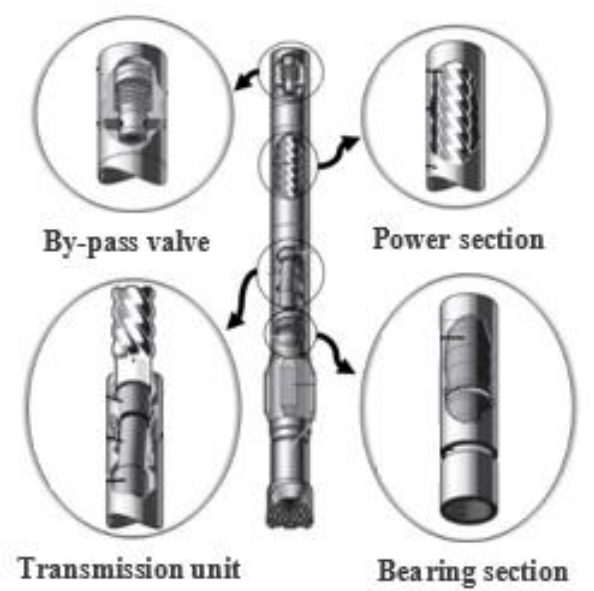

Figure 2. Downhole motor with its main components, stabilizer, and bit (Halliburton, 2001).
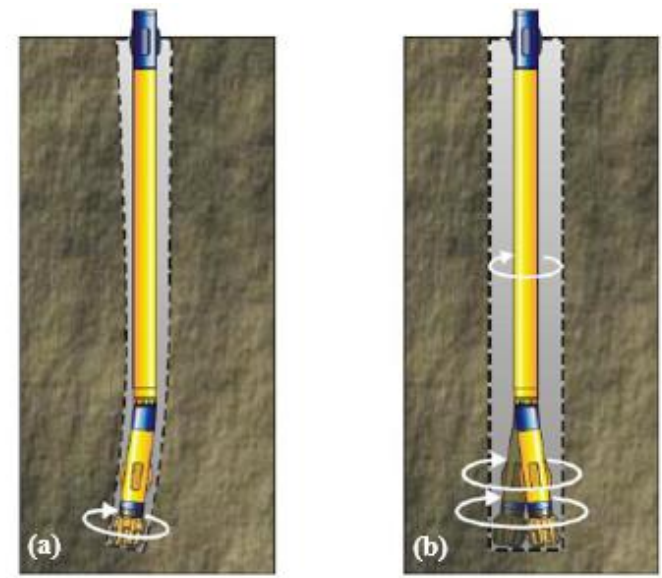

Figure 3. Steerable drilling through the modes: (a) Sliding and (b) Rotating (Inteq/Baker Hughes, 2002).

bent housing, and this set is associated with the use of a continuous measurement equipment. This system is considered an important advance in well trajectory control, as it allows changes in the directional characteristics of the well without the removal of the drill string for modification of the bottom-hole assembly. According to Lourenço Jr (2012), the steerable system can be triggered in two different ways: by sliding or rotating mode, shown in Figure 3.

In the sliding mode, Figure 3(a), the downhole motor is directed from the rotation of the drill string through the rotary table. The spin of the string is not meant to drill; it has the purpose of positioning the tool face. The string is rotated until the desired direction is obtained (Lourenço Jr, 2012). With the tool face positioned correctly, the rotary table is locked and drilling follows. The direction is kept constant and the bit is rotated by the downhole motor. When the direction and the desired final inclination are reached, the rotating mode is activated, Figure $3(\mathrm{~b})$. In this mode, the rotary table is unlocked so that the drill string rotates in the same way as with common drilling.

Some advantages found in the use of a steerable system are:

- Large distance intervals, with variations in rock formation, can be drilled without the need to withdraw the string to tool replacement;

- Improvement in drilling performance, due to the torque over the bit;

- Reduction of risk of differential sticking.

However, the use of a steerable system presents some problems related to each drive mode, such as:

- It reduces the penetration rate due to the greater friction with the wellbore;

- It can cause slight break-in from the well, due to the bent sub/bent housing;

- The transition between rotating and sliding modes can create dog legs, that is, variations in the trajectory;

- Regarding the sliding drilling mode, it creates a risk of drill string sticking and leads to wellbore cleanup inefficiency due to the fact that the drill string stays supported on the bottom of the cross section of the well the entire time;

- When it comes to the rotating mode, vibrations can cause motor failures, high bit and string wear, and can lead to an irregular well diameter.

\subsubsection{Rotary Steerable System (RSS)}

The rotary steerable system (RSS) presents an operation similar to the steerable system and is considered the evolution of it. However, RSS allows the string to rotate throughout the drilling process, even in the sections of gain or loss of angle, and changes in direction. Their main components are: non-rotating steerable stabilizer, control stabilize, and measurement while drilling tool; as shown in Figure 4. 


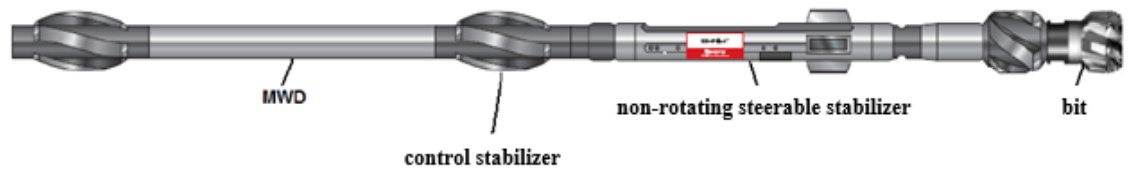

Figure 4. Main components of a rotary steerable system (Halliburton, 2019).

According to Clyde et al. (2008), some advantages of the system are:

- Allowing better penetration rate;

- Promoting a more efficient wellbore cleanup, since the rotation of the string contributes a lot to the suspension of the cuttings;

- Creating lower torque and drag, which creates better weight transfer to the bit;

- Allowing the change in the trajectory of the well in any direction and inclination with controlled rate, without having to stop the string rotation; and

- Reducing time on the operation.

\section{MATERIALS AND METHODS}

For the development of this work, we considered the drilling of the $83 / 4$ in diameter phase of an onshore directional hole, comprised between $197 \mathrm{~m}$ and $957 \mathrm{~m}$. For drilling the phase, we used a bottom-hole assembly composed with the following equipment:

- Tricone bit;

- Downhole motor with bent housing;

- Sub;

- Drill collar;

- MWD;

- Stabilizer;

- Heavy-weights drill pipes (HWDP);

- Jar; and

- Drill pipes.

Considering the drilling of this phase, we compared the use of a downhole motor or rotary steerable system, maintaining all other parameters.

For the downhole motor, there is a variation between rotating and sliding mode during operation, generating different penetration rate values at each drilled depth. ROP is obtained by Equation (1):

$R O P=\frac{\Delta L}{\Delta t}$

Where $\Delta \mathrm{L}$ represents the depth drilled, in meters, and $\Delta t$ the time it was drilled, in hours.

The average penetration rate in meters per hour $(\mathrm{m} / \mathrm{h})$ for each mode, rotating and sliding, was calculated using Equations (2) and (3), respectively:

$$
\begin{aligned}
& R O P_{\text {rot }}=\left(\sum_{r=1}^{n} R O P_{r}\right) / n \\
& R_{O P P_{\text {ori }}}=\left(\sum_{\text {or }=1}^{m} R O P_{\text {or }}\right) / m
\end{aligned}
$$

Being:

- $R O P_{\text {rot }}$ : average penetration rate for rotating mode;

- $R O P_{\text {ori }}:$ average penetration rate for sliding mode;

- $R O P_{r}$ : penetration rate values obtained when using rotating mode during the operation;

- $R O P_{\text {or }}$ : penetration rate values obtained when using the sliding mode during the operation;

- $n$ : number of intervals presented for penetration rate in rotating mode;

- $m$ : number of intervals presented for the penetration rate in sliding mode.

By applying the general definition of ROP given in Equation (1) for the average penetration rates of each mode, the drilled depth (L), in meters (m), 


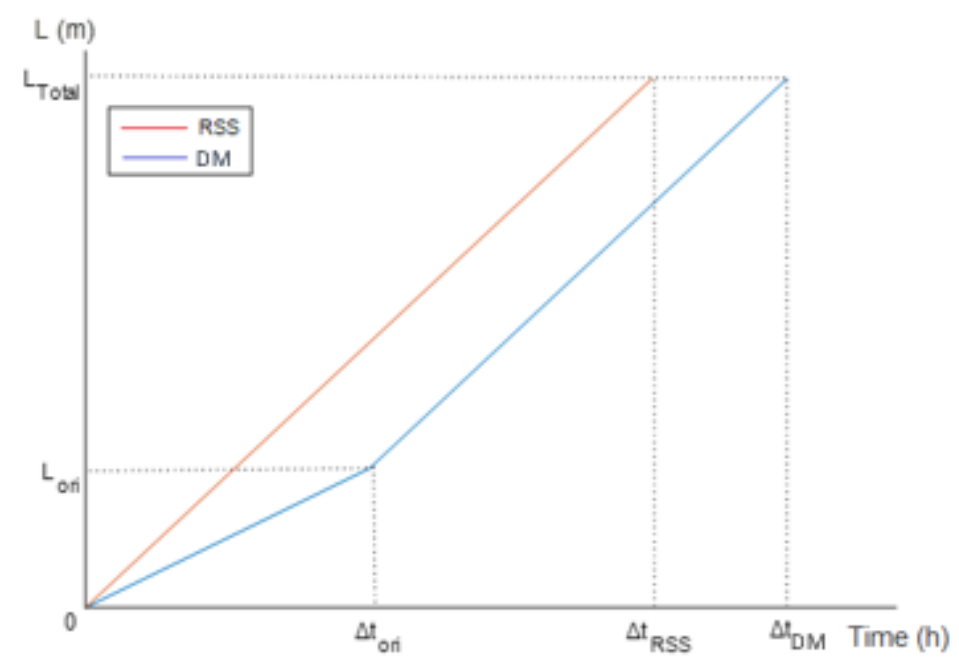

Figure 5. Depth (L) vs. time $(\Delta \mathrm{t})$ plot for drilling with downhole motor and RSS.

was obtained as a function of the average ROP, in meters per hour $(\mathrm{m} / \mathrm{h})$, for each method, and as a function of the time consumed $(\Delta t)$, in hours $(h)$, as shown in Equations (4) and (5):

$L_{\text {rot }}=R O P_{\text {rot }} \Delta t_{\text {rot }}$

$L_{\text {ori }}=R O P_{\text {ori }} \Delta t_{\text {ori }}$

With that:

$L_{\text {total }}=L_{\text {rot }}+L_{\text {ori }}$

Substituting Equations (4) and (5) in Equation (6), we obtained, for a drilling operation using a downhole motor:

$L_{\text {total }}=R O P_{\text {rot }} \Delta t_{\text {rot }}+R O P_{\text {ori }} \Delta t_{\text {ori }}$

The analysis referring to the drilling operation using the rotary steerable system considers the same data employed as in the operation with downhole motor, without the use of sliding mode, that is, a drilling $100 \%$ in rotating mode. Thus:

$L_{\text {total }}=R O P_{\text {rot }} \Delta t_{R S S}$

Where $L_{\text {total }}$ represents the total drilled depth, in meters $(\mathrm{m}), R O P_{\text {rot }}$ is the average rotating mode penetration rate, the same as the one found in downhole motor operation, in meters per hour $(\mathrm{m} / \mathrm{h})$, and $\Delta t_{R S S}$ is the time required for the drilling with the RSS. Thus, Depth $(L)$ versus Time $(\Delta t)$ graph was generated to compare both equipment, as shown in Figure (5).

By means of Figure (5), and isolating the variable $t$ in Equations (7) and (8), we have:
$\Delta t_{R S S}=\frac{L_{\text {total }}}{R O P_{\text {rot }}}$

$\Delta t_{D M}=\frac{L_{\text {total }}-\Delta t_{\text {ori }}\left(R O P_{\text {ori }}-R O P_{\text {rot }}\right)}{R O P_{\text {rot }}}$

Being,

$\Delta t_{\text {rot }}=\Delta t_{D M}-\Delta t_{\text {ori }}$

Where $\Delta t_{\text {rot }}$ is the time used in rotating mode, $\Delta t_{D M}$ the total operating time with the downhole motor, and $\Delta t_{\text {ori }}$ the operating time in sliding mode.

Parallel to this scenario, in the analysis performed in this study, the cost of the deviation tool used and the daily cost of the drilling rig were considered as operating costs. The daily cost of a downhole motor is US\$ 2,024.33/24 circulated hours, not considering the trip performed during the operation. The price of using RSS tool is 5 times the value of the downhole motor, that is, US\$ $10,121.66 / 24$ circulated hours. These values were based on the quotation of one US dollar, equivalent to $R \$ 3.83$ as of June 22,2019 . For the rigs, daily prices are shown in Table 1.

Table 1. Daily costs of drilling rigs.

\begin{tabular}{cc}
\hline Rig Type & Value (US\$/day) \\
\hline $\begin{array}{c}\text { Small Rigs } \\
\text { (for wells up to 2000m) } \\
\text { Large Rigs }\end{array}$ & $30,000.00$ \\
\hline
\end{tabular}


Thus, we defined that:

$$
\begin{aligned}
& C_{R S S}=\left(5 V_{D M} \Delta t_{R S S}\right)+\left(V_{S} \Delta t_{\text {drill }}\right) \\
& C_{D M}=\left(V_{D M} \Delta t_{D M}\right)+\left(V_{S} \Delta t_{\text {drill }}\right)
\end{aligned}
$$

Where:

- $C_{R S S}$ : Cost of operation using the rotary steerable system;

- $C_{D M}$ : Cost of operation using downhole motor;

- $V_{D M}$ : Daily cost of the downhole motor;

- $V_{S}$ : Daily cost of the drilling rig;

- $\Delta t_{R S S}:$ RSS usage time, in hours (h);

- $\Delta t_{D M}$ : Downhole motor running time in hours (h);

- $\Delta t_{\text {drill }}$ : Total drilling operation time, in days.

Replacing Equations (9) and (10) in Equations (12) and (13), gives Equations (14) and (15), which represent the cost of the operation as a function of drilled depth and ROP, for RSS and downhole motor, respectively:

$$
\begin{aligned}
& C_{R S S}=5 V_{D M} \frac{\left(L_{\text {total }}\right)}{R O P_{\text {rot }}}+\left(V_{S} \Delta t_{\text {drill }}\right) \\
& C_{D M}=V_{D M} \frac{\left[L_{\text {total }}-\Delta t_{\text {ori }}\left(R O P_{\text {ori }}-R O P_{\text {rot }}\right)\right]}{R O P_{\text {rot }}}+ \\
& +\left(V_{S} \Delta t_{\text {drill }}\right)
\end{aligned}
$$

Thereby, the graph of operation costs using each equipment is presented, as a function of the time of use of each one, shown in Figure 6.

As shown in Figure 6, for both curves, at a time $\Delta t=1 \mathrm{~h}$, there will already be an operating cost, since equipment and rig values are given daily. The RSS curve, represented by the black color, follows the parameters of Equation (14), and becomes constant when reaching the end of the well, completing the drilling. The downhole motor curve, represented by red and blue colors, and by Equation (15), has an operating cost 5 times lower when compared to the RSS. It also presents a smaller slope. The red part represents the use of downhole motor with a sliding mode. It corresponds to up to $30 \%$ of the total time. As this percentage increases, the blue curve begins and, with that, there is also an increase in total operating time. Thus, at a given time $(\Delta t)$, the cost curve of the operation using the downhole motor will intercept the cost curve of the operation using RSS. This means that, from this moment, the use of a rotary steerable system will become more economically advantageous if compared to the use of the downhole motor.

To make the process of obtaining more practical results, the calculations covered in all equations presented previously were executed through programming codes and graphs developed in the MatLab software.

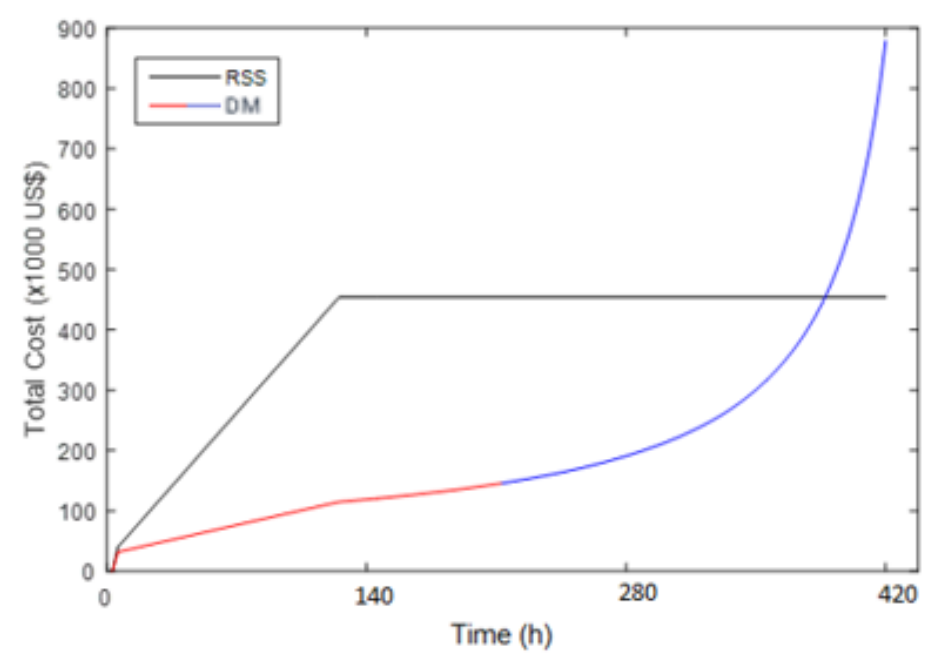

Figure 6. Operation cost graph using downhole motor and RSS, as a function of the time of use of each equipment. 


\section{RESULTS AND DISCUSSIONS}

From the data analyzed and using Equations (2) and (3), the average penetration rates were calculated for each drilling mode, when the downhole motor was used in the operation. The drilled depth $(L)$ in meters $(\mathrm{m})$ was acquired using each method, and the time consumed $(\Delta t)$ in hours (h) was obtained through equations (4) and (5). All values achieved are shown in Table 2.

For the drilling operation using the rotary steerable system, the results found through the use of Equation (8) for average penetration rate, drilled depth $(L)$ in meters $(\mathrm{m})$, and time consumed $(\Delta t)$ in hours $(\mathrm{h})$, are presented in Table 3.

The graph in Figure (5) and Tables 2 and 3 demonstrate that the operation performed with the rotary steerable is achieved in a shorter time, when compared to the same operation performed with the downhole motor. This result is due to the fact that RSS works in a $100 \%$ rotating mode, and, thus, it generates better penetration rates, increasing the drilled depth at a given time.

Based on the ROP values shown in Tables 2 and 3 , and in Equations (14) and (15) for the total cost of the operation performed with each of the equipment, it was possible to obtain a graph of the total costs of each operation as a function of the usage time (Figure 7).

The graph displayed in Figure 7 shows that for the analyzed data, the use of a downhole motor for directional drilling will be more advantageous than using a rotary steerable system. Since the total operation cost curves using each of the equipment do not intersect, the costs of using the downhole motor will always be lower.

The curves assumed a step aspect due to the fact that the equipment and the drilling rig are charged daily. Thus, costs only increase after completing 24 hours of use of each one.

Under this assumption, we found a $R O P_{\text {ori }}$ value for which the use of RSS becomes economically viable. The result is shown in Figure 8.

Based on Equations (14) and (15) for the total operation cost reached with each equipment, a value of $R O P_{\text {ori }}=3.26 \mathrm{~m} / \mathrm{h}$ was found for the
Table 2. Average penetration rate, drilled depth, and time consumed for rotating and sliding modes when using downhole motor for drilling operations.

\begin{tabular}{cccc}
\hline Mode & $\boldsymbol{\Delta L}(\mathrm{m})$ & $\boldsymbol{\Delta t}(\mathrm{h})$ & $\mathrm{ROP}(\mathrm{m} / \mathrm{h})$ \\
\hline Rotating & 600 & 33.1 & 18.13 \\
Sliding & 160 & 16.8 & 9.52 \\
Total & 760 & 49.9 & \\
\hline
\end{tabular}

Table 3. Average penetration rate, drilled depth, and time consumed when using RSS for drilling operations.

\begin{tabular}{cccc}
\hline Mode & $\Delta \mathrm{L}(\mathrm{m})$ & $\boldsymbol{\Delta t}(\mathrm{h})$ & $\mathrm{ROP}(\mathrm{m} / \mathrm{h})$ \\
\hline Rotating & 760 & 41.92 & 18.13 \\
\hline
\end{tabular}

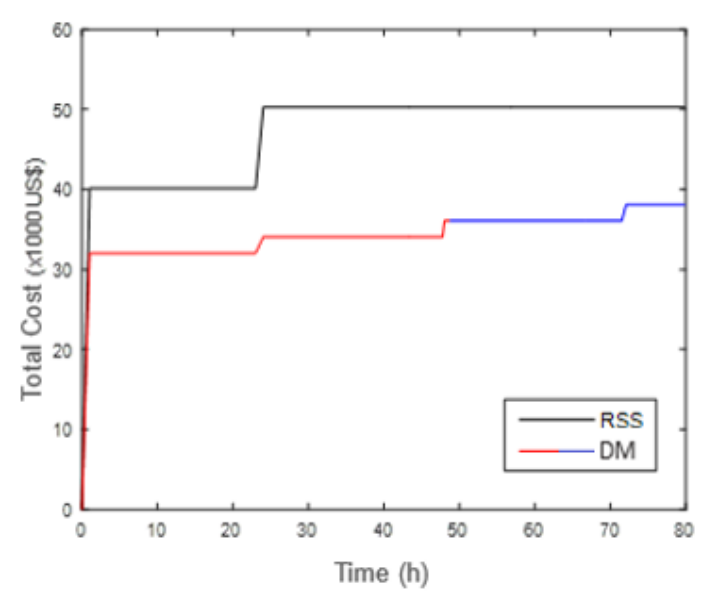

Figure 7. Operation cost graph using downhole motor and RSS, as a function of the usage time of each equipment, for a value of $\boldsymbol{R O P} \boldsymbol{P}_{\text {ori }}=9.52 \mathrm{~m} / \mathrm{h}$.

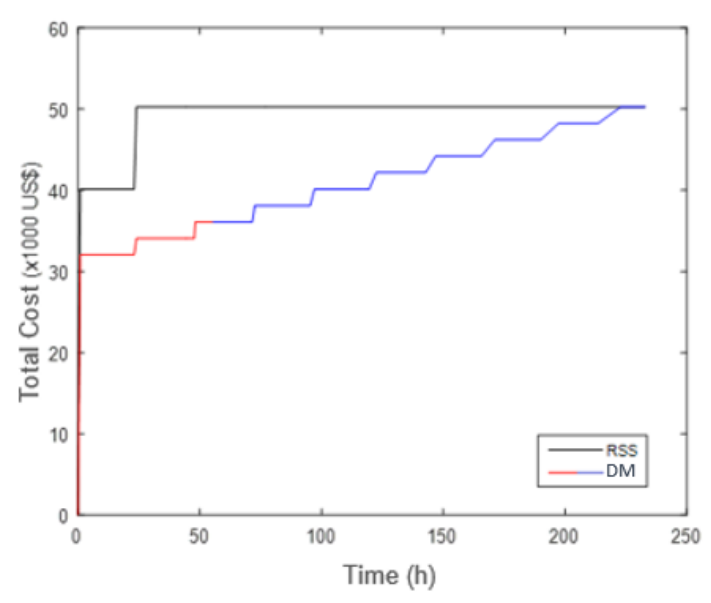

Figure 8. Operation cost graph using downhole motor and RSS, as a function of the usage time of each equipment, for a value of $\boldsymbol{R O P}$ ori $=3.26 \mathrm{~m} / \mathrm{h}$. 


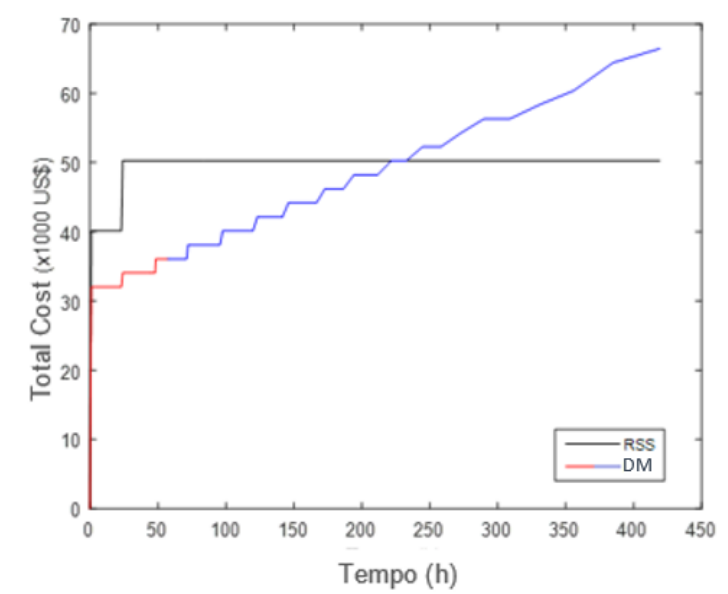

Figure 9. Operation cost graph using downhole motor and RSS, as a function of the usage time of each equipment, for a value of $\boldsymbol{R O} \boldsymbol{P}_{\text {ori }}=1.81 \mathrm{~m} / \mathrm{h}$.

moment when the total operation cost curve using the downhole motor will intercept the cost curve using RSS. Therefore, this is the maximum value of $R O P_{\text {ori }}$, so that the use of the downhole motor on the operation is preferable when compared to using an RSS. However, this value is inconsistent with practice, as it is lower than the lowest penetration rate value achieved when using the sliding mode during the operation with downhole motor.

To evidence the results, even smaller values of $R O P_{\text {ori }}$ were tested, shown in Figure 9.

The relations presented in the graph prove that the use of a rotary steerable system will be more advantageous for lower values of $R O P_{\text {ori }}$ when using a downhole motor for the same operation.

\section{CONCLUSIONS}

After conducting a comparative study between penetration rates when using the downhole motor and rotary steerable system tools in an $83 / 4$ in onshore directional hole, comprised between 197 $\mathrm{m}$ and $957 \mathrm{~m}$, we can conclude that:

- The use of a downhole motor in a drilling operation will be more advantageous than using a rotary steerable system, because, despite its longer operation time, the higher cost of the rotary steerable system does not justify its use;
- The average penetration rate obtained in the sliding mode with the use of downhole motor should be less than $3.26 \mathrm{~m} / \mathrm{h}$ to make the use of RSS more advantageous; and

- The lower the $R O P_{\text {ori }}$ value achieved when using a downhole motor is, the more cost effective replacing this equipment with a rotary steerable system will, even though the RSS has a higher cost.

\section{REFERENCES}

Almeida, E. L. F. Dinâmica Tecnológica das Indústrias Energéticas. Apostila Didática. Instituto de Economia/UFRJ. Rio de Janeiro, 2002. (in Portuguese).

Amorim Jr, D. S. Metodologia para a Redução de Custos na Perfuração de Poços de Petróleo e Gás. Dissertação de Mestrado. POLI-USP, São Paulo, 2008. (in Portuguese)

Azar, J. J.; Samuel, G.R. Drilling Engineering. Tulsa: PennWell Corporation, 2007.

Chen, D. Directional Drilling. In: Lake, L. W.; Mitchell, R. F. (Editors). Petroleum Engineering Handbook. Richardson: Society of Petroleum Engineers. v. 2. cap. 6, 2006.

Clyde, R.; D’Ambrosio, P.; Perez, M.A.; Israel, R.; Leavit, T.; Nutt, L.; Williamson, D.; Johnson, C. Meeting the Subsalt Challenge. Oilfield Review, v. 20(3), p. 32-45, 2008.

Ebrahimi, M.; Noveiri, E. Cost per Foot Reduction by Bit Run Optimization: A Simulation Study. In: Trinidad \& Tobago Energy Resources. Conference, Port of Spain - Trinidad \& Tobago, 2010. https://doi.org/10.2118/133429-MS

Férnandez, E. F.; Pinho, A. C.; Pedrosa, O. A. Dicionário de Petróleo em Língua Portuguesa. $1^{\text {st }}$ ed. 656p. Editora Lexikon, 2009. (in Portuguese)

HALLIBURTON. Sperry Drill Technical Information Handbook. $2^{\text {nd }}$ Ed., p. 369. Guide to Operation - Halliburton Energy Services, 2001.

HALLIBURTON. Rotary Steerable Systems. Available at: www.halliburton.com. Accessed on: 11 de maio de 2019. 
INTEQ/BAKER HUGHES. Drilling Engineering Workbook. EUA, 1995.

INTEQ/BAKER HUGHES. Navi - Drill Motor Handbook. EUA, 2002.

Küng, S. C. Previsão de Taxas de Penetração na Perfuração de Poços de Petróleo com Brocas de Cortadores Fixos. Dissertação de Mestrado. Programa de Pós-Graduação em Engenharia Civil, Universidade Federal do Rio de Janeiro, 2016. (in Portuguese)

Lourenço Jr, H. V. Técnicas de Perfuração. Programa Alta Competência. Recursos Humanos/Universidade Petrobras. 2012. (in Portuguese)

Machado, J. B. Curso Básico de Perfuração Direcional. Halliburton, 2010. (in Portuguese)

Mims, T. K. M. Drilling Design and Implementation for Extended Reach and Complex Wells. $2^{\text {nd }}$ ed. Houston, Texas: K\&M Technology Group, LLC, 1999.
Paes, P.; Aragão, A.; Chen, D. C. K. Cost-effective drilling optimization technologies in Campos Basin. SPE Latin American and Caribbean Petroleum Engineering Conference, SPE-94785-MS, 20-23 June, Rio de Janeiro, Brazil, 2005.

https://doi.org/10.2118/94785-MS

Rocha, L. A. S. Perfuração Direcional. $2^{\text {nd }}$ ed, 342p. Rio de Janeiro: Interciência: Petrobras: IBP, 2008. (in Portuguese)

Thomas, J. E. Fundamentos de Engenharia de Petróleo. 2ed. Rio de Janeiro: Interciência, 2001. (in Portuguese)

Willson, S.M.; Driscoll, P.; Judzis, A.; Black, A.; Martin, W.; Ehgartner, B.; HinkebeinN, T. Drilling salt formations offshore with seawater can significantly reduce well costs. SPE Drilling \& Completion, v. 19(3), p. 147-155, SPE-87216-PA, 2004. https://doi.org/10.2118/87216-PA 